\title{
The use of grafted seedlings increases the success of conservation translocations of Manglietia longipedunculata (Magnoliaceae), a Critically Endangered tree
}

\author{
Hai Ren, Hong Liu, Jun Wang, Lianlian Yuan, Xiaodong Cui \\ Qianmei Zhang, Lin Fu, Hongfeng Chen, Wenchao Zhong \\ KEMING YANG and QINFEng GuO
}

\begin{abstract}
The distribution of the Critically Endangered tree Manglietia longipedunculata, of which there are only 11 known wild individuals, is restricted to the Nankunshan Nature Reserve in South China. The species is threatened with extinction because of its small number of individuals and the impediments to its reproduction (a combination of protogyny, a short period of stigma receptivity, and a lack of efficient pollinators). To reduce the risk of extinction we conducted two conservation translocation trials: one to augment the sole extant population, and the other $202 \mathrm{~km}$ north of the current range. The latter trial was a conservation introduction in which the goals were to increase the population and to buffer against the effects of climate change. We used emerged and grafted seedlings as translocation materials. We compared the survival, growth, and eco-physiological properties of emerged and grafted seedlings at the two sites. The survival rate and growth were higher for grafted seedlings than for emerged seedlings at both sites. Eco-physiological data indicated that grafted seedlings at both sites were as efficient or more so in light and water usage than wild individuals, whereas emerged seedlings were less efficient. Grafted seedlings attained the flowering stage sooner than emerged seedlings. Our study suggests that grafting can facilitate the augmentation and establishment of new populations of $M$. longipedunculata and perhaps of new populations of other
\end{abstract}

Hai Ren (Corresponding author), Jun Wang, Lianlian Yuan, Qianmei Zhang, LiN Fu, Hongfeng Chen and Keming Yang Key Laboratory of Vegetation Restoration and Management of Degraded Ecosystems, South China Botanical Garden, Chinese Academy of Sciences, Guangzhou 510650, China

E-mail renhai@scbg.ac.cn

HoNG LIU Department of Earth and Environment, Florida International University, International Center for Tropical Botany, Miami, Florida, USA, and Forestry College, Guangxi University, Nanning, China

Xiaodong Cui and Wenchao Zhong Administration of Nankunshan Nature Reserve, Longmeng, China

QINFENG Guo Southern Research Station, USDA Forest Service, Asheville, North Carolina, USA

Received 13 November 2014. Revision requested 7 January 2015

Accepted 16 March 2015. First published online 25 May 2015. threatened species facing reproductive difficulties and climate change.

Keywords China, conservation introduction, ecological restoration, Manglietia longipedunculata, plant conservation technique, point endemic species, threatened species

\section{Introduction}

Tor threatened plants with extremely small populations, - conservation translocations are part of a suite of conservation measures including stabilizing or increasing population size, reducing extinction risk and supporting adaptation to climate change (Maschinski \& Haskins, 2012; Ren et al., 2012a). Translocation can thus contribute to the Global Strategy for Plant Conservation targets of '6o percent of threatened plant species in accessible ex situ collections, preferably in the country of origin, and 1o percent of them included in recovery and restoration programmes' (Secretary of the Convention on Biodiversity, 2005).

There are three main types of conservation translocation (IUCN/SSC, 2013): augmentation, in which individuals are added to an existing population to increase the population size or genetic diversity; reintroduction, in which individuals of a species are released into an area formerly inhabited by the species; and conservation introduction (also known as managed relocation, assisted colonization, and assisted migration), in which individuals of a species are transferred from the existing distribution area to new areas that are not part of the historical distribution. Conservation introduction may be of particular importance for species that have narrow and/or fragmented distributions and that are unable to shift to higher latitudes in response to global warming because of dispersal barriers and loss of important pollinators (Hunter, 2007; Loss et al., 2011).

Translocation of threatened species to locations outside their native ranges in response to projected climate change is controversial (Seddon, 2010; Hewitt et al., 2011). Some 
conservation biologists doubt that threatened species can survive outside their native ranges, and others worry about the potential negative effects of the translocated species on the recipient community. Nevertheless, preliminary evidence indicates that conservation introductions can help certain threatened species establish new populations without significant negative effects on the extant biological community (Liu et al., 2012; Maschinski \& Haskins, 2012).

The success of an introduction or reintroduction depends on how demographic, genetic and other ecological factors affect the individual plant and the population (Godefroid et al., 2011; Cogoni et al., 2013). Furthermore, successful translocation depends on the propagule type and source used as transplant material, and on site preparation (Akeroyd \& Jackson, 1995). Whole plants (wild or cultivated), seedlings, cuttings or seeds are commonly used as the transplant materials (Wendelberger et al., 2008). Plant propagules prepared in ex situ facilities are seldom fully adapted to their natural habitat and require a period of acclimatization (Maschinski \& Haskins, 2012). Although horticulturists have found that grafted seedlings are hardier and acclimatize faster than seedlings that emerge from seeds (Lee et al., 2010), grafted seedlings have seldom been used in conservation translocation (Ren et al., 2014a).

Manglietia longipedunculata Q. W. Zeng \& Law, family Magnoliaceae, is an evergreen, canopy tree (Plate 1). Currently it is found only in the evergreen broad-leaved forest at the Nankunshan Nature Reserve, Longmen County, Guangdong Province, South China (Fig. 1). A thorough survey of the whole Reserve during 2007-2008 found only 11 individuals of the species in the wild; these are re-sprouts from stumps that were logged many years ago, and are scattered (Zeng \& Law, 2004; Xie et al., 2011). The species is included on the Red List of Magnoliaceae (Cicuzza et al., 2007). Manglietia longipedunculata has considerable horticultural and economic potential, being an aesthetically appealing tree with large flowers, red fruit and attractive foliage (Xie et al., 2011; Plate 1). It also provides high-quality timber (which is why it was logged).

The low reproductive success of $M$. longipedunculata can be explained by a combination of protogyny (the maturation of the pistil before the stamens have matured their pollen), a short period of stigma receptivity, and a lack of efficient insect pollinators (Xie et al., 2011). The wild-flowering trees are currently unable to produce fruit under natural conditions. Researchers suspect that current climatic conditions, and an increase in mean temperature in particular, may be partially responsible for the lack of pollinators at the site of the extant population. At present, seeds can only be obtained through artificial pollination, and only $50 \%$ of such seeds are viable (Fang et al., 2006); the surviving seedlings, however, can grow in either shade or full sunlight.

To help conserve $M$. longipedunculata and to determine the effectiveness of various conservation measures we

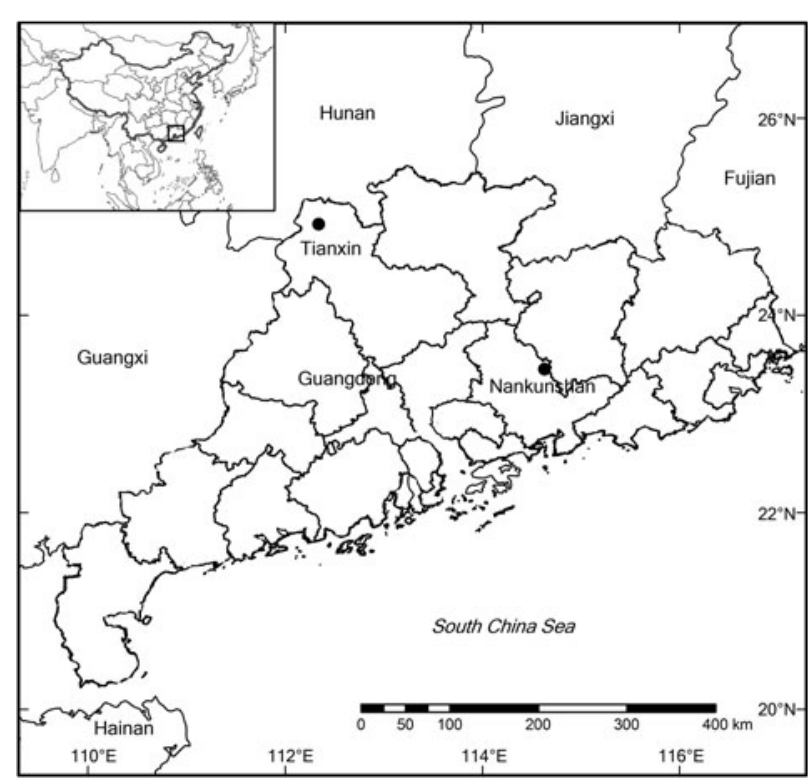

Fig. 1 Locations of Nankunshan and Tianxin in Guangdong Province, South China. The rectangle on the inset indicates the location of the main figure in China.

carried out two conservation translocation trials. In an augmentation trial we attempted to increase the number of individuals at the site of the extant population. In an introduction trial we attempted to establish a population at a new site at a higher latitude, which would have been too cool in the past but which may be at suitable temperatures in the future as a result of climate change. Both trials involved transplanting $M$. longipedunculata individuals produced ex situ. As transplant material we used and compared seedlings that emerged from seeds (hereafter referred to as emerged seedlings) and grafted seedlings. Our objectives were to compare the survival, growth and ecophysiological traits of grafted seedlings vs emerged seedlings, and to compare seedling performance at the two sites.

\section{Study area}

The study was conducted simultaneously at the 1,750 ha Nankunshan Nature Reserve (hereafter referred to as Nankunshan) and the 12,000 ha Tianxin Nature Reserve (hereafter referred to as Tianxin), Guangdong Province, southern China (Fig. 1). Nankunshan, in Longmen County, has a lower subtropical monsoon climate, with mean annual temperature of $20.8^{\circ} \mathrm{C}$ and mean annual rainfall of $2,163 \mathrm{~mm}$. It is located within the lateritic soil zone and the lower subtropical broad-leaved forest vegetation zone. Manglietia longipedunculata has been found at 700-80o $\mathrm{m}$ altitude (Xie et al., 2011). We surveyed all existing individuals of $M$. longipedunculata during March 2010 and June 2013 at the experimental sites in Nankunshan. The plant community containing the wild specimens 
TABLE 1 Characteristics of the site of the original population and of the sites used for augmentation and a conservation introduction of Manglietia longipedunculata in South China (Fig. 1).

\begin{tabular}{|c|c|c|c|}
\hline Characteristic & $\begin{array}{l}\text { Original population } \\
\text { site (Nankunshan) }^{1}\end{array}$ & $\begin{array}{l}\text { Augmentation site } \\
\text { (Nankunshan) }^{2}\end{array}$ & $\begin{array}{l}\text { Translocation site } \\
(\text { Tianxin })^{2}\end{array}$ \\
\hline Canopy cover $(\%)$ & 80 & 0 & 0 \\
\hline Soil type & Lateritic & Lateritic & Lateritic \\
\hline Soil water content $(\%)$ & $23.3-35.2$ & $21.2-30.5$ & $24.2-36.8$ \\
\hline $\mathrm{pH}($ mean $\pm \mathrm{SD})$ & $4.7 \pm 0.5$ & $4.7 \pm 0.3$ & $4.8 \pm 0.3$ \\
\hline Total nitrogen (mean \pm SD, \%) & $0.11 \pm 0.05$ & $0.12 \pm 0.03$ & $0.10 \pm 0.02$ \\
\hline Total phosphorous (mean \pm SD, \%) & $0.03 \pm 0.02$ & $0.03 \pm 0.02$ & $0.05 \pm 0.01$ \\
\hline Total potassium $($ mean $\pm \mathrm{SD}, \%)$ & $2.70 \pm 0.30$ & $1.20 \pm 0.33$ & $0.09 \pm 0.03$ \\
\hline Soil organic matter (mean $\pm S D, \%)$ & $2.70 \pm 0.21$ & $2.65 \pm 0.35$ & $2.20 \pm 0.18$ \\
\hline Relative humidity (\%) & 80 & 80 & 78 \\
\hline Mean annual temperature $\left({ }^{\circ} \mathrm{C}\right)$ & 20.8 & 20.8 & 19.5 \\
\hline Mean annual rainfall (mm) & 2,163 & 2,163 & 1,571 \\
\hline Elevation $(\mathrm{m})$ & $700-800$ & 382 & 280 \\
\hline
\end{tabular}

${ }^{1}$ Dominant species: Manglietia moto, Manglietia pachyphylla, Michelia maudiae, Litsea verticillata, Castanopsis lamontii, Castanopsis fabric

${ }^{2}$ Cleared forest stand, with some herbs

of $M$. longipedunculata is a secondary tropical evergreen broad-leaved forest dominated by Manglietia moto, Manglietia pachyphylla, Michelia maudiae, Litsea verticillata, Castanopsis lamontii and Castanopsis fabric. The canopy of this community is continuous, with c. $80 \%$ canopy cover. The 11 individuals of $M$. longipedunculata were widely scattered. The mean height and diameter at breast height of the 11 individuals were $13.1 \pm$ SD $3.3 \mathrm{~m}$ and $23.1 \pm \mathrm{SD} 11.1$ $\mathrm{cm}$, respectively. All 11 individuals were mature and had sprouted from stumps left after trees had been cut many years earlier. No seedlings or small plants of the species were found under the mature individuals.

Tianxin is located in Lianzhou City and has a central subtropical monsoon climate. It is at $130-450 \mathrm{~m}$ altitude and is $202 \mathrm{~km}$ from Nankunshan. The mean annual temperature is $19.5^{\circ} \mathrm{C}$, and mean annual rainfall is $1,571 \mathrm{~mm}$. Tianxin is located within a lateritic soil zone. The vegetation is dominated by evergreen broadleaved forests typical of the subtropics. Representative plant families of the climax community at Tianxin include Lauraceae, Euphorbiaceae and Fagaceae (Ren et al., 2012b). The soils at Nankunshan and Tianxin have similar chemical properties: low $\mathrm{pH}$ values, low total phosphorous content, and high total nitrogen and organic matter contents (Table 1).

\section{Methods}

\section{Plant materials}

Two mature re-sprouted individuals from one $M$. longipedunculata stump at Nankunshan were artificially pollinated in June 2008, and seeds were collected in September 2008. The seeds from these artificial pollinations were sown immediately in the nursery of the magnolia garden of the
South China Botanical Garden. Approximately 1,400 emerged seedlings were raised successfully.

In 2008 we grafted 200 M. longipedunculata scions $(2-3 \mathrm{~cm}$ each) to 200 rootstocks of 1-year-old Manglietia moto. The scions were obtained from the largest wild plant, which was the only individual that was large enough for us to collect scions without threatening its survival. Of the 200 grafted plants, 190 grew successfully.

In March 2009 we planted 100 of each type of seedling (emerged and grafted) at Nankunshan and 45 of each type of seedling at Tianxin, as described in the next section. All the planted seedlings were healthy, similar in size, and selected randomly.

\section{Experimental design}

We conducted an augmentation experiment at Nankunshan and a conservation introduction experiment at Tianxin. The augmentation plots in Nankunshan were 300 m lower than the extant population; this site was selected to facilitate comparison with the Tianxin plot. We selected plots with similar soil properties. The plots are located in the experimental area of the Reserve and have no native flora of special concern.

At each site (Nankunshan and Tianxin) a 1 ha experimental field was divided into three blocks. Each block contained two $50 \times 30 \mathrm{~m}$ plots, one of which was planted with emerged seedlings and the other with grafted seedlings. Plants were separated by $2 \mathrm{~m}$ within rows and by $3 \mathrm{~m}$ between rows. We planted 33 or 34 emerged seedlings or grafted seedlings in each plot at Nankunshan, and 15 in each plot at Tianxin. We watered the seedlings only three times (on the first, third, and seventh days after transplantation). As M. longipedunculata seedlings are sun-tolerant, 
we cleared all trees and shrubs from all plots before the seedlings were transplanted, to eliminate competition. The plots were not fenced, fertilized or mulched, and were left unmanaged after the initial clearing and planting.

\section{Demographic performance}

We recorded the height and diameter at soil level of each transplant immediately after transplanting and once per year for the next 5 years. Once per year we also recorded whether individual plants were still alive. If a transplant was dead we inferred whether death was caused by insect defoliation, fungal decay, nutrient deficiency, lack of water, or strong radiation, based on its appearance.

\section{Eco-physiological performance}

Eco-physiological performance of translocated individuals can determine their survival and growth rate. Ecophysiological indicators can also distinguish differences in adaptability between emerged and grafted seedlings. We therefore measured key indicators (light-use and water-use efficiencies of the transplants), on sunny days at Nankunshan on 3 and 4 June 2013 and at Tianxin on 12 and 13 June 2013. For these measurements we selected three seedlings at random in each plot. We selected one sun-exposed mature leaf from each of these seedlings, and compared these leaves in terms of their eco-physiological characteristics.

To study the photosynthetic mechanism and physiological conditions of plants, we measured chlorophyll fluorescence parameters of photosystem II (PSII) with a portable, pulse-amplitude, modulated fluorometer (PAM-210o, Walz, Effeltrich, Germany; Liang et al., 2010). Following Souza et al. (2004) and Han et al. (2005) we measured actual photochemical efficiency $\left(\Phi_{\text {PSII }}\right)$, photochemical fluorescence quenches ( $\mathrm{qP}$ ) and non-photochemical fluorescence quenches (qN).

To measure the light-energy and water-use efficiency of plants we took microclimate and leaf gas exchange measurements. The quantity of solar irradiance received by the plants differed among the experiment sites. Environmental factors (PAR, photosynthetically active radiation; $T_{\mathrm{a}}$, air temperature; $\mathrm{RH}$, air relative humidity; $C_{\mathrm{a}}$, air $\mathrm{CO}_{2}$ concentration) were measured by sensors on a portable photosynthesis system (LI-640o, Li-Cor, Lincoln, USA) for 1 whole day at each site (Liang et al., 2010).

Net photosynthetic rate $\left(P_{\mathrm{n}}\right)$, stomatal conductance $(g s)$, intercellular $\mathrm{CO}_{2}$ concentration $\left(C_{\mathrm{i}}\right)$, and transpiration rate $(E)$ were measured for attached leaves on a sunny day, at 2-hour intervals during 08.00-18.00, using the LI-6400 system. Water-use efficiency was calculated as $P_{\mathrm{n}} / E$ (Dewar, 1997). Stomata limitation $\left(L_{\mathrm{s}}\right)$ was calculated as $1-C_{\mathrm{i}} / C_{\mathrm{a}}$ (Berry \& Downton, 1982). To compare the maximum photosynthetic rate, the light compensation point and the light saturation point among the sites under consistent conditions, a uniform $\mathrm{CO}_{2}$ concentration $\left(380 \mu \mathrm{mol} \mathrm{mol}^{-1}\right)$ and temperature $\left(25^{\circ} \mathrm{C}\right)$ were maintained in the $\mathrm{Li}-6400$ leaf chamber, and the net photosynthesis response curve was determined at PAR values of $0-2,000 \mu \mathrm{mol} \mathrm{m}^{-2} \mathrm{~s}^{-1}$ (Walker, 1989).

\section{Statistical analysis}

The survival curve data (March 2009-June 2014) were analysed using Kaplan-Meier tests, which is the simplest way of comparing seedling survival over time. It involves computing probabilities of occurrence of an event at a certain point in time, and multiplying these successive probabilities by any earlier computed probabilities to obtain the final estimate (Goel et al., 2010). We then calculated the proportion of seedlings that survived in the final census for each plot. We used two-way ANOVA to compare the mean percentage of seedling survival between the two sites and seedling type. The differences between individual treatments (e.g. grafted vs emerged, and Nankunshan vs Tianxin) were assessed using a post-hoc Tukey test at $\mathrm{P}<0.05$. For the analysis of differences in eco-physiological properties, a multiple comparison test (least significant difference) was used when ANOVAs were significant at $\alpha=0.05$. All statistical tests were performed using SPSS 13.0 for Windows (SPSS, Chicago, USA).

\section{Results}

\section{Survival of transplanted seedlings}

The survival rate of transplanted seedlings was relatively stable after 1 year and exceeded $64 \%$ after 5 years at both sites and for both types of seedlings (Fig. 2). According to Kaplan-Meier estimates, the probability of survival over time of both emerged seedlings and grafted seedlings was higher at Nankunshan than at Tianxin (Table 2). The percentage survival at the last census for grafted seedlings (95 \pm SD $4 \%$ ) was greater than that for emerged seedlings at both sites ( $75 \pm$ SD $3 \%$; Fig. 2 ). The survival rate was marginally higher for grafted seedlings at Nankunshan than at Tianxin. All of these differences were statistically significant, as indicated by post-hoc pair-wise Tukey tests (Table 2), between the various treatments.

\section{Growth and reproductive performance of transplanted seedlings}

The grafted seedlings grew faster than the emerged seedlings at both sites (Fig. 2b,c). Both the grafted seedlings and the emerged seedlings grew faster at Nankunshan than at 

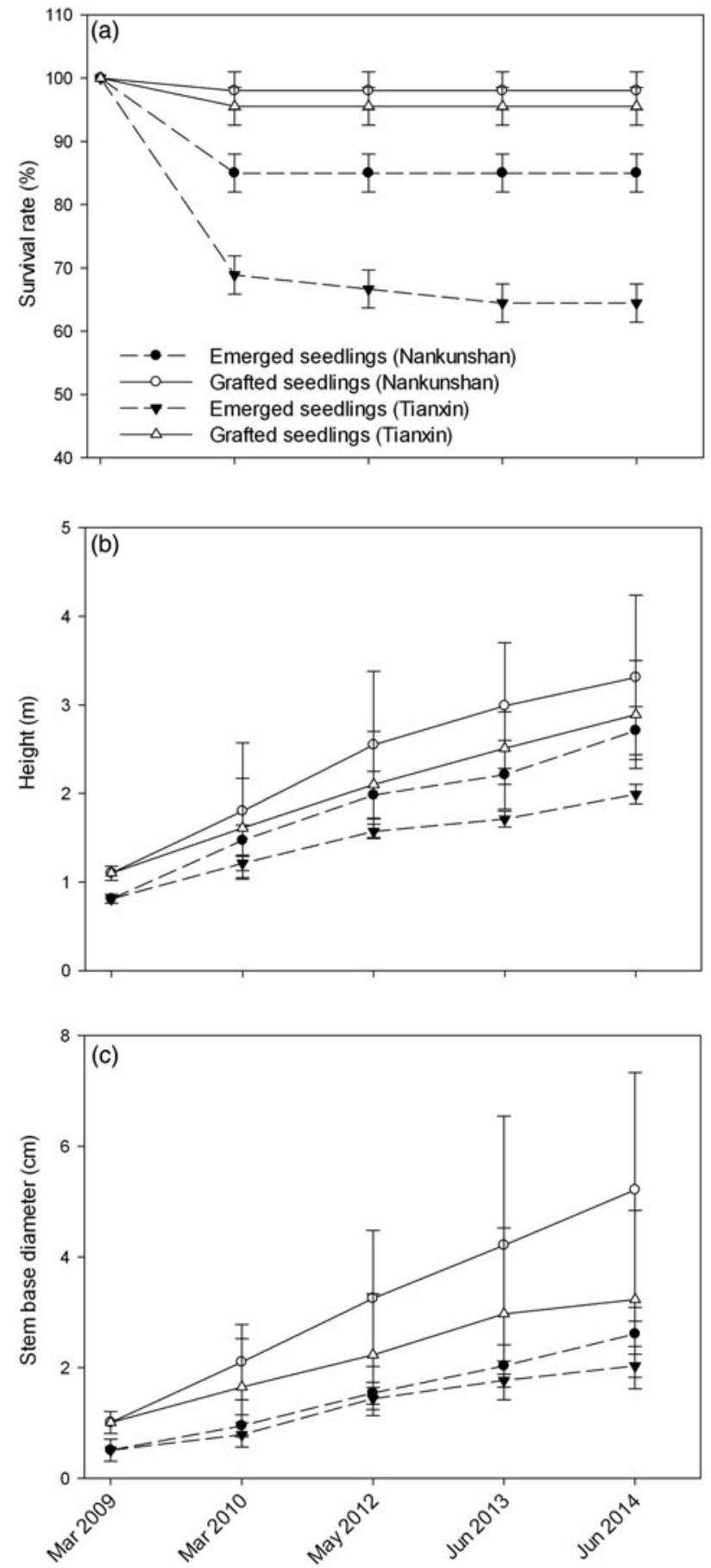

FIG. 2 (a) Survival of seedlings (mean \pm SD) of Manglietia longipedunculata transplanted to Nankunshan and Tianxin (Fig. 1) in March 2009, and (b) changes in height and (c) diameter at soil level (mean \pm SD) of the transplanted seedlings during March 2009-June 2014.

Tianxin. All of these differences were statistically significant (Table 2) between the various treatments. The height and diameter at soil level of grafted seedlings at both sites showed more size differentiation than that of emerged seedlings (Fig. 2b,c). Lack of water appeared to be the only cause of transplant mortality.
Four of the grafted seedlings at Nankunshan first bloomed in May 2012, and one of the grafted seedlings at Tianxin first bloomed in May 2014. After we failed to observe any natural pollinators at the sites, we hand-pollinated the five flowers, which then produced fruit with seeds.

\section{Eco-physiological characteristics}

Chlorophyll fluorescence parameters differed significantly among the $M$. longipedunculata leaves obtained from the five combinations of seedling type and site: wild mature trees at Nankunshan, emerged seedlings at Nankunshan, grafted seedlings at Nankunshan, emerged seedlings at Tianxin, and grafted seedlings at Tianxin $(\mathrm{P}<0.05$; Table 3). Compared with the emerged seedlings, the grafted seedlings and wild mature trees had higher $\mathrm{Fv} / \mathrm{Fm}$ and $\Phi_{\mathrm{PSII}}$ values. $F \mathrm{v} / F \mathrm{~m}$ and $\Phi_{\mathrm{PSII}}$ values were similar for grafted seedlings and wild mature trees at Nankunshan. The grafted seedlings at Tianxin had lower $F \mathrm{v} / F \mathrm{~m}, \Phi_{\mathrm{PSI}}$ and $\mathrm{qP}$ values but higher $\mathrm{qN}$ values than grafted seedlings at Nankunshan. The pattern was similar for emerged seedlings.

Maximum photosynthetic rates and water-use efficiencies were higher for grafted seedlings and wild mature trees than for emerged seedlings $(\mathrm{P}<0.05)$ but did not differ significantly between grafted seedlings and wild mature trees. In addition, the light saturation point $(\mathrm{P}<0.05)$ and light compensation point were lower for the grafted seedlings at Tianxin than for the grafted seedlings or wild mature trees at Nankunshan (Table 3).

\section{Discussion}

The current knowledge gap and the relevance of this study

Until now few studies have tested the success of using translocation of grafted seedlings as a conservation measure for threatened trees. Grafting is a technique used frequently for vegetative propagation of horticultural crops because of its many benefits, including avoidance of juvenility, size control, and biotic and abiotic stress resistance (Harada, 2010). Grafting has been used for thousands of years to propagate fruit trees (Lee et al., 2010) but the grafting of seedlings of rare and threatened plants has been used for conservation translocations only recently (Ren et al., 2014b). Although incompatibility may appear at later stages and lead to tree death, grafting can be used to generate a large number of seedlings in a relatively short time, and grafted seedlings usually grow faster and are more tolerant of abiotic stresses than conventional seedlings (Lee et al., 2010).

Our study demonstrated that grafting can be successful for M. longipedunculata. Although both the grafted and 

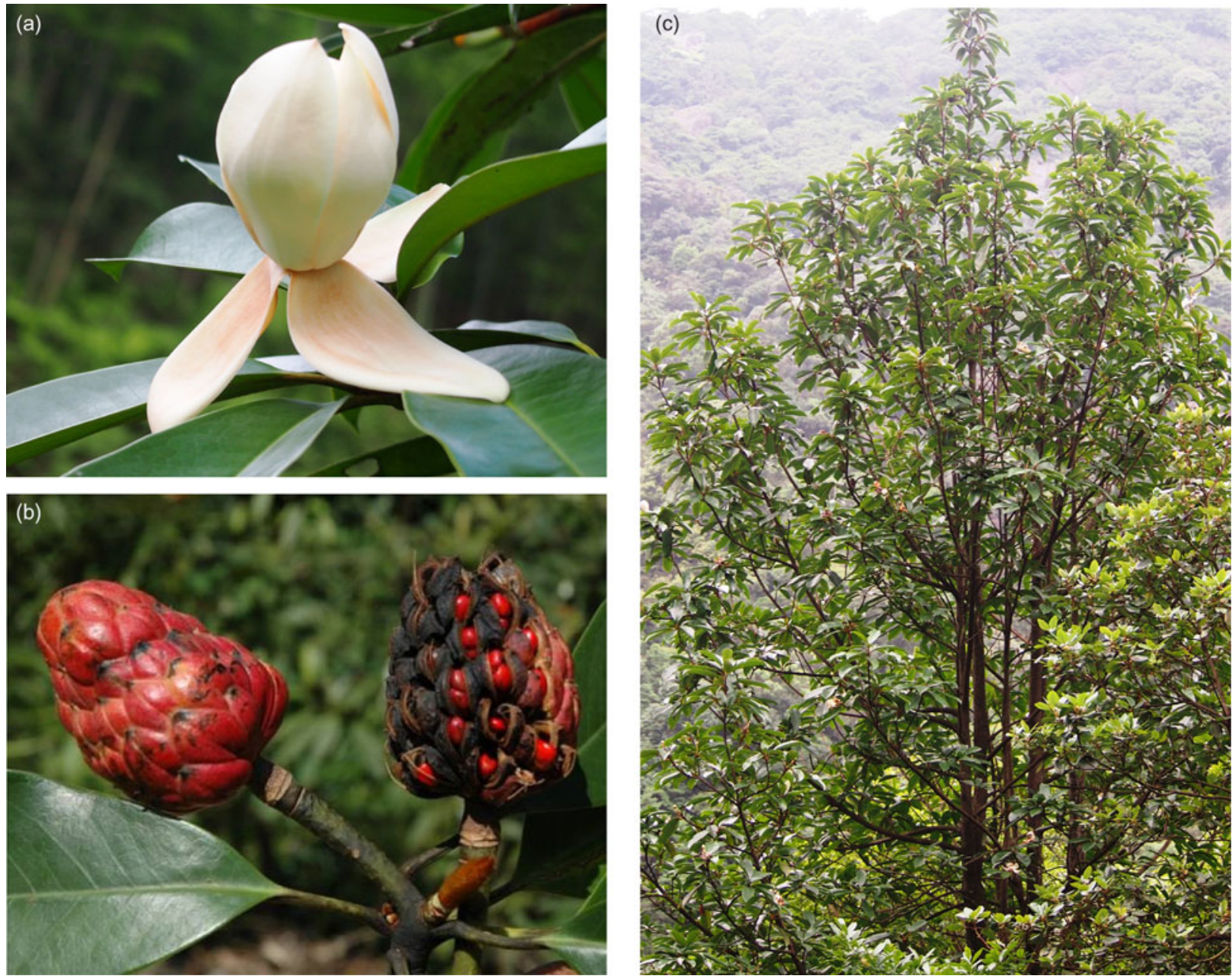

Plate 1 The flower (a) and fruit (b) of Manglietia longipedunculata, and a mature wild individual (c).

TABLE 2 Results of pair-wise comparisons (ANOVA with post hoc Tukey test, $\mathrm{P}=0.05$ ) of the effects of site (Nankunshan vs Tianxin) and treatment (grafted vs emerged) on survival and growth of $M$. longipedunculata seedlings, and Kaplan-Meier survival probability estimates for the seedlings.

\begin{tabular}{llllll}
\hline Seedling type (location) & $\begin{array}{l}\text { Survival rate } \\
(\text { mean } \pm \text { SD, \%) }\end{array}$ & $\begin{array}{l}\text { Height } \\
(\text { mean } \pm \mathrm{SD}, \mathrm{m})\end{array}$ & $\begin{array}{l}\text { Estimated probability } \\
\text { of death }\end{array}$ & $\begin{array}{l}\text { Estimated probability } \\
\text { of survival }\end{array}$ & $\begin{array}{l}\text { Probability of survival } \\
\text { at the end of the study }\end{array}$ \\
\hline Grafted (Nankunshan) & $98 \pm 6^{\star} \#$ & $3.31 \pm 0.93^{\star} \#$ & 0.068 & 0.932 & 0.871 \\
Grafted (Tianxin) & $96 \pm 4^{\star} \#$ & $2.89 \pm 0.61^{\star} \#$ & 0.088 & 0.912 & 0.732 \\
Emerged (Nankunshan) & $85 \pm 3^{\star} \#$ & $2.71 \pm 0.27^{\star} \#$ & 0.248 & 0.752 & 0.489 \\
Emerged (Tianxin) & $64 \pm 5^{\star} \#$ & $1.99 \pm 0.11^{\star} \#$ & 0.373 & 0.627 & 0.335 \\
\hline
\end{tabular}

${ }^{*} \mathrm{P}<0.05$ vs seedling treatment, \#P<0.05 vs site

emerged seedlings of $M$. longipedunculata survived and grew well at both experimental sites, grafted seedlings showed better survival and growth at each site. In addition, grafted seedlings had superior eco-physiological performance and thus were better able to adapt to abiotic stress and reach flowering age earlier than the emerged seedlings. This suggests that grafting may be an appropriate technique for future in situ augmentation and conservation translocations of $M$. longipedunculata and perhaps of other rare species facing similar reproductive obstacles.

\section{Implications for genetic diversity}

In this study all grafted seedlings came from one individual tree. Future efforts may require reintroducing grafted or 
TABLE 3 Mean values of chlorophyll fluorescence parameters and photosynthetic parameters measured from three mature wild individuals of M. longipedunculata at Nankunshan and 7-9 grafted and emerged seedlings at both Nankunshan (the augmentation site) and Tianxin (the conservation introduction site) in South China (Fig. 1). Values in a given row are not significantly different from one another if they share the same letter; values with different letters are significantly different $(\mathrm{P}<0.05)$.

\begin{tabular}{|c|c|c|c|c|c|}
\hline & $\begin{array}{l}\text { Grafted seedlings } \\
\text { (Nankunshan) }\end{array}$ & $\begin{array}{l}\text { Grafted seedlings } \\
\text { (Tianxin) }\end{array}$ & $\begin{array}{l}\text { Emerged seedlings } \\
\text { (Nankunshan) }\end{array}$ & $\begin{array}{l}\text { Emerged seedlings } \\
\text { (Tianxin) }\end{array}$ & $\begin{array}{l}\text { Wild mature trees } \\
\text { (Nankunshan) }\end{array}$ \\
\hline \multicolumn{6}{|c|}{ Chlorophyll fluorescence parameters } \\
\hline $\begin{array}{l}\text { Maximal photochemical } \\
\text { efficiency of PSII, Fv/Fm } \\
\text { (mean } \pm \text { SE) }\end{array}$ & $0.804 \pm 0.035 \mathrm{a}$ & $0.789 \pm 0.047 a$ & $0.733 \pm 0.048 b$ & $0.706 \pm 0.032 b$ & $0.797 \pm 0.041 \mathrm{a}$ \\
\hline $\begin{array}{l}\text { Actual photochemical efficiency, } \\
\Phi_{\text {PSII }}(\text { mean } \pm \text { SE })\end{array}$ & $0.565 \pm 0.118 \mathrm{a}$ & $0.476 \pm 0.085 b$ & $0.392 \pm 0.123 c$ & $0.331 \pm 0.124 c$ & $0.543 \pm 0.078 \mathrm{ab}$ \\
\hline $\begin{array}{l}\text { Photochemical fluorescence } \\
\text { quenches, qP (mean } \pm \text { SE) }\end{array}$ & $0.870 \pm 0.072 b$ & $0.981 \pm 0.034 \mathrm{a}$ & $0.737 \pm 0.112 c$ & $0.736 \pm 0.089 c$ & $0.900 \pm 0.054 b$ \\
\hline $\begin{array}{l}\text { Non-photochemical fluorescence } \\
\text { quenches, qN (mean } \pm \text { SE) }\end{array}$ & $2.949 \pm 0.662 \mathrm{a}$ & $0.839 \pm 0.067 \mathrm{~d}$ & $2.170 \pm 0.330 \mathrm{~b}$ & $1.806 \pm 0.410 \mathrm{c}$ & $2.343 \pm 0.436 b$ \\
\hline \multicolumn{6}{|l|}{ Photosynthetic parameters } \\
\hline $\begin{array}{l}\text { Maximum photosynthetic rate, } \\
\mu \mathrm{mol} \mathrm{m}{ }^{-2} \mathrm{~s}^{-1}(\text { mean } \pm \mathrm{SE})\end{array}$ & $16.789 \pm 1.821 \mathrm{a}$ & $16.204 \pm 0.891 \mathrm{a}$ & $8.272 \pm 0.288 b$ & $6.960 \pm 0.471 b$ & $17.479 \pm 1.504 \mathrm{a}$ \\
\hline $\begin{array}{l}\text { Dark respiration rate, } \mu \mathrm{mol} \\
\mathrm{m}^{-2} \mathrm{~s}^{-1}(\text { mean } \pm \mathrm{SE})\end{array}$ & $1.173 \pm 0.368 c$ & $2.595 \pm 0.546 b$ & $1.467 \pm 0.191 c$ & $3.621 \pm 0.313 a$ & $1.844 \pm 0.461 b c$ \\
\hline $\begin{array}{l}\text { Water use efficiency, } \mu \mathrm{mol} \\
\mathrm{mol}^{-1}(\text { mean } \pm \mathrm{SE})\end{array}$ & $108.632 \pm 15.685 a$ & $105.332 \pm 9.043 a$ & $98.56352 \pm 12.017 b$ & $93.059 \pm 7.019 b$ & $103.066 \pm 9.018 \mathrm{a}$ \\
\hline $\begin{array}{l}\text { Light compensation point, } \\
\mu \mathrm{mol} \mathrm{m} \mathrm{m}^{-2} \mathrm{~s}^{-1}\end{array}$ & $37.8 \mathrm{c}$ & $20.8 \mathrm{c}$ & $28.2 \mathrm{bc}$ & $61.4 \mathrm{a}$ & $27.9 \mathrm{bc}$ \\
\hline $\begin{array}{l}\text { Light saturation point, } \\
\qquad \mu \mathrm{mol} \mathrm{m} \mathrm{m}^{-2} \mathrm{~s}^{-1}\end{array}$ & $1,200 \mathrm{a}$ & $1,000 \mathrm{~b}$ & $800 \mathrm{c}$ & $800 c$ & $1,200 \mathrm{a}$ \\
\hline $\begin{array}{l}\text { Instantaneous light use efficiency, } \\
\quad \mu \mathrm{mol} \mathrm{mmol} \\
-1 \\
(\text { mean } \pm \mathrm{SE})^{*}\end{array}$ & $15.021 \pm 4.106 \mathrm{a}$ & $13.423 \pm 4.640 \mathrm{a}$ & $6.885 \pm 2.924 b$ & $3.021 \pm 0.648 c$ & $13.323 \pm 3.949 \mathrm{a}$ \\
\hline
\end{tabular}

${ }^{\star}$ Measured under light intensity $500-1,400 \mu \mathrm{mol} \mathrm{m}^{-2} \mathrm{~s}^{-1}$

emerged seedlings from other wild individuals to the translocation population to improve the genetic diversity of the species. Genetic diversity within such a small population is necessary to provide a basis for adaptation to changing environments (Reed \& Frankham, 2003; Falk et al., 2006). Genetic diversity is vital to establish translocation populations with high levels of fitness and the greatest probability of long-term success (Bouzat, 2010). Some guidelines for plant reintroductions recommend collecting locally, and not mixing population sources in outplanting (Sanders \& McGraw, 2005), whereas others encourage mixing within a reasonable geographical distance (Maschinski et al., 2013). For M. longipedunculata all available individuals should be used in future reintroductions as they are from a single, albeit scattered, population.

\section{Results of translocation experiment}

Climate change may limit our options for conserving rare plant species in their natural habitats, and the premise of translocation is that threatened species can be moved to locations where the future climate is predicted to be more favourable for their persistence (Maschinski \& Haskins, 2012).
Our conservation introduction of seedlings of $M$. longipedunculata from the species' original location (Nankunshan) was to a site (Tianxin) that is colder $\left(\right.$ by $1.4^{\circ} \mathrm{C}$ ) and drier (c. $600 \mathrm{~mm}$ less rainfall annually). Although seedlings planted in Nankunshan had higher survival probability, growth rate and physiological performance, grafted seedlings were successful at both sites. With the expectation that future temperatures will be more suitable for M. longipedunculata at Tianxin than at Nankunshan, our results provide preliminary support for conservation introduction as a viable option for maintaining the species in the wild.

Generally, when introducing a rare and threatened species to a location outside its known range it is important to find optimal sites for long-term survival, growth, reproduction and establishment of new populations (Falk et al., 1996; McKay et al., 2005; Millar et al., 2007). Identifying appropriate habitat is therefore essential to establish sustainable populations in new locations. A recipient site can be assessed using reference sites, usually sites where there are extant populations (Maschinski \& Wright, 2006), as in this study. Habitat similarity involves many factors, such as climate, soil, dominant ecosystem processes, and interspecific interactions (Lawrence \& Kaye, 2011). For M. longipedunculata 
the soil and regional climate are important; identifying similarities to Nankunshan in the site selected at Tianxin proved effective for successful translocation.

Translocating species beyond their recorded native ranges is an option when traditional strategies are inadequate. However, there is a risk that translocated species could become invasive in their new ranges (Ricciardi \& Simberloff, 2009; Thomas, 2011). Manglietia longipedunculata remains rare in the region to which seedlings were translocated; nevertheless, we will continue monitoring this population and any effects it may have on the recipient site.

A key qualitative measure of the ultimate success of reintroductions is the ability of transplanted seedlings to flower and set fruit (Godefroid et al., 2011). Successful reintroduction also depends on pollination and dispersal; reintroduced individuals must do more than survive, they must also reproduce and disperse. Conventional methods, such as habitat protection and restoration, are not always sufficient to prevent population decline or extinction of a rare and threatened plant if aspects of the plant's biology or geographical barriers restrict natural recolonization or dispersal (Wang et al., 2009; Choi et al., 2012; Sheean et al., 2012; Li et al., 2014). We recommend that artificial pollination be used to increase fruit set and to help the population disperse both in situ and ex situ. In agreement with IUCN/SSC (2013), we also recommend that more introductions should be implemented to augment existing small populations.

Manglietia longipedunculata faces extinction because of human disturbance and obstacles to its reproduction (Xie et al., 2011). We recommend an integrated conservation plan for this species that includes patrolling Nankunshan to prevent plant removal, establishing (with the aid of grafting) an ex situ living collection that contains the entire genetic diversity of the wild population, facilitating $M$. longipedunculata propagation for commercial use, and implementing augmentation and translocation. Our study has shown that grafting can enhance the adaptability of the propagation material, and facilitate the augmentation of existing populations and establishment of new populations of M. longipedunculata.

\section{Acknowledgements}

This research was supported by the National Natural Science Foundation of China (31170493, 31360146), Guangdong Science and Technology Programme (2013Bo60400016, 2010B060200039), and the Guangxi Science and Technology Bureau (grant no. 12217-04). We are grateful to Prof. Qingwen Zeng, Dr Chen Xiuzi and $\mathrm{Mr}$ Zhixin Tang at the Administration of Tianxin Provincial Natural Reserve for the field investigation. We also thank Prof. Bruce Jaffee and Ms Elizabeth Platt for editing the English, and constructive comments.

\section{References}

Akeroyd, J. \& Jackson, P.W. (1995) A Handbook for Botanic Gardens on the Reintroduction of Plants to the Wild. Botanic Gardens Conservation International, Richmond, UK.

BERry, J.A. \& Downton, W.J.S. (1982) Environmental regulation of photosynthesis. In Photosynthesis, Volume II (ed. E. Govindjee), pp. 263-343. Academic Press, New York, USA.

Bouzat, J.L. (2010) Conservation genetics of population bottlenecks: the role of chance, selection, and history. Conservation Genetics, 11, $463-478$.

Chol, H.J., JANG, H.D., IsAGI, Y. \& OH, B.Y. (2012) Distribution and conservation status of the Critically Endangered Scrophularia takesimensis, a plant endemic to Ulleung Island, Republic of Korea. Oryx, 46, 399-402.

Cicuzza, D., Newton, A. \& Oldfield, S. (2007) The Red List of Magnoliaceae. Fauna \& Flora International, Cambridge, UK.

Cogoni, D., Fenu, G., Concas, E. \& Bacchetta, G. (2013) The effectiveness of plant conservation measures: the Dianthus morisianus reintroduction. Oryx, 47, 203-206.

DEWAR, R.C. (1997) A simple model of light and water use evaluated for Pinus radiata. Tree Physiology, 17, 259-265.

Falk, D.A., Millar, C.I. \& Olwell, M. (eds) (1996) Restoring Diversity: Strategies for Reintroduction of Endangered Plants. Island Press, Washington, DC, USA.

Falk, D.A., Palmer, M.A. \& Zedler, J.B. (eds) (2006) Foundations of Restoration Ecology. Island Press, Washington, DC, USA.

FANG, X.P., XU, J. \& YANG, C.H. (2006) Propagation of seeds of ornamental plants in Magnoliaceae family. Seed, 5, 54-56.

Godefroid, S., Piazza, C., Rossi, G., Buord, S., Stevens, A.-D., Aguraiuja, R. et al. (2011) How successful are plant species reintroductions? Biological Conservation, 144, 672-682.

Goel, M.K., Khanna, P. \& Kishore, J. (2010) Understanding survival analysis: Kaplan-Meier estimate. International Journal of Ayurveda Research, 1, 274-278.

HAN, Z.G., LEI, L.M. \& HAN, B.P. (2005) In situ monitoring of chlorophyll fluorescence using PAM fluorometer. Ecological Science, 3, 246-249. [In Chinese, with English abstract]

Harada, T. (2010) Grafting and RNA transport via phloem tissue in horticultural plants. Scientia Horticulturae, 125, 545-550.

Hewitt, N., Klenk, N., Smith, A.L., Bazely, D.R., Yan, N., Wood, S. et al. (2011) Taking stock of the assisted migration debate. Biological Conservation, 144, 2560-2572.

Hunter, JR, M.L. (2007) Climate change and moving species: furthering the debate on assisted colonization. Conservation Biology, 21, $1356-1358$.

IUCN/SSC (2013) Guidelines for Reintroductions and Other Conservation Translocations. Version 1.o. IUCN Species Survival Commission, Gland, Switzerland.

Lawrence, B.A. \& Kaye, T.N. (2011) Reintroduction of Castilleja levisecta: effects of ecological similarity, source population genetics, and habitat quality. Restoration Ecology, 19, 166-176.

Lee, J.M., Kubota, C., Tsao, S.J., Bie, Z., Echevarria, P.H., Morra, L. \& ODA, M. (2010) Current status of vegetable grafting: diffusion, grafting techniques, automation. Scientia Horticulturae, 127, 93-105.

LI, B., ZHANG, Z.Y. \& ZHANG, D.X. (2014) Conservation status of the unique population of Wenchengia alternifolia, an enigmatic plant endemic to Hainan Island, China. Oryx, 48, 354-357.

LiAnG, K.M., Lin, Z.F., Ren, H., LiU, N., ZhanG, Q.M., WANG, J. et al. (2010) Characteristics of sun- and shade-adapted populations of an endangered plant, Primulina tabacum Hance. Photosynthetica, 48, 494-506.

LiU, H., Feng, C.L., Chen, B.S., Wang, Z.S., Xie, X.Q., Deng, Z.H. et al. (2012) Overcoming extreme weather challenges: successful but 
variable assisted colonization of wild orchids in southwestern China. Biological Conservation, 150, 68-75.

Loss, S.R., Terwilliger, L.A. \& Peterson, A.C. (2011) Assisted colonization: integrating conservation strategies in the face of climate change. Biological Conservation, 144, 92-100.

Maschinski, J. \& Haskins, K.E. (eds) (2012) Plant Reintroduction in a Changing Climate: Promises and Perils. Island Press, Washington, DC, USA.

Maschinski, J. \& Wright, S.J. (2006) Using ecological theory to plan restorations of the endangered beach jacquemontia (Convolvulaceae) in fragmented habitats. Journal for Nature Conservation, 14, 180-189.

Maschinski, J., Wright, S.J., Koptur, S. \& Pinto-Torres, E.C. (2013) When is local the best paradigm? Breeding history influences conservation reintroduction survival and population trajectories in times of extreme climate events. Biological Conservation, 159, 277-284.

McKay, J.K., Christian, C.E., Harrison, S. \& Rice, K.J. (2005) "How local is local?" A review of practical and conceptual issues in the genetics of restoration. Restoration Ecology, 13, 432-440.

Millar, C.I., Stephenson, N.L. \& Stephens, S.L. (2007) Climate change and forests of the future: managing in the face of uncertainty. Ecological Applications, 17, 2145-2151.

Reed, D.H. \& Frankham, R. (2003) Correlation between fitness and genetic diversity. Conservation Biology, 17, 230-237.

Ren, H., Zhang, Q.M., Lu, H.F., Liu, H.X., Guo, Q.F., WanG, J. et al. (2012a) Wild plant species with extremely small populations require conservation and reintroduction in China. AMBIO, 41, 913-917.

Ren, H., ZenG, S.J., Li, L.N., Zhang, Q.M., YANG, L., WANG, J. et al. (2012b) Reintroduction of Tigridiopalma magnifica, a rare and Critically Endangered herb endemic to China. Oryx, 46, 391-398.

Ren, H., Jian, S.G., LiU, H.X., ZhanG, Q.M. \& Lu, H.F. (2014a) Advances in the reintroduction of rare and endangered wild plant species. Science China Life Sciences, 57, 603-609.

Ren, H., Jian, S.G., Chen, Y.J., LiU, H., Zhang, Q.M., LiU, N. et al. (2014b) Distribution, status, and conservation of Camellia changii Ye (Theaceae), a Critically Endangered, plant endemic to southern China. Oryx, 48, 358-36o.

Ricciardi, A. \& Simberloff, D. (2009) Assisted colonization is not a viable conservation strategy. Trends in Ecology and Evolution, 24, 248-253.

Sanders, S. \& McGraw, J.B. (2005) Population differentiation of a threatened plant: variation in response to local environment and implications for restoration. Journal of the Torrey Botanical Society, 132, 561-572.

Secretary of the Convention on Biodiversity (2005) The Global Strategy for Plant Conservation. Secretary of the Convention on Biodiversity, Montreal, Canada.
Seddon, P.J. (2010) From reintroduction to assisted colonization: moving along the conservation translocation spectrum. Restoration Ecology, 18, 796-802.

Sheean, V.A., Manning, A.D. \& Lindenmayer, D.B. (2012) An assessment of scientific approaches towards species relocations in Australia. Austral Ecology, 37, 204-215.

Souza, R.P., Machado, E.C., Silva, J.A.B., LagôA, A.M.M.A. \& Silveira, J.A.G. (2004) Photosynthetic gas exchange, chlorophyll fluorescence and some associated metabolic changes in cowpea (Vigna unguiculata) during water stress and recovery. Environmental Experimental Botany, 51, 45-56.

Tном As, C.D. (2011) Translocation of species, climate change, and the end of trying to recreate past ecological communities. Trends in Ecology and Evolution, 26, 216-221.

W ALKER, D.A. (1989) Automated measurement of leaf photosynthetic $\mathrm{O}_{2}$ evolution as a function of photon flux density. Philosophical Transactions of the Royal Society of London B, 323, 313-326.

WANG, J., Ren, H., YANG, L. \& DUAN, W.J. (2009) Establishment and early growth of introduced indigenous tree species in typical plantations and shrubland in South China. Forest Ecology and Management, 258, 1293-1300.

Wendelberger, K.S., Fellows, M.Q.N. \& Maschinski, J. (2008) Rescue and restoration: experimental translocation of Amorpha herbacea Walter var. crenulata (Rybd.) Isley into a novel urban habitat. Restoration Ecology, 16, 542-552.

XiE, C., FU, L. \& ZENG, Q.W. (2011) Studies on conservation of rare and endangered species Manglietia longipedunculata (Magnoliaceae). In Proceedings of the 2nd International Symposium on the Family Magnoliaceae (eds N.H. Xia, Q.W. Zeng, F.X. Xu \& Q.G. Wu), pp. 149-162. Huazhong Science and Technology University Press, Wuhan, China.

Zeng, Q.W. \& LAW, Y.W. (2004) Manglietia longipedunculata (Magnoliaceae), a new species from Guangdong, China. Annales Botanici Fennici, 41, 151-154.

\section{Biographical sketches}

$\mathrm{HAI}_{\mathrm{REN}}$ is interested in vegetation restoration and reintroductions of rare and threatened plant species. HONG LIU has been carrying out research in biodiversity conservation in the USA and China for 15 years. JUN WANG is interested in forest restoration. LIANLIAN YUAN focuses on plant eco-physiology. XIAODONG CUI is in charge of in situ conservation and of the nursery at Nankunshan Nature Reserve. Qianmei $\mathrm{ZHANG}_{\mathrm{H}}$ is a data analyst with an interest in long-term ecological studies. Lin Fu, Hongfeng Chen, Wenchao Zhong and Keming YANG conduct field monitoring. QINFENG GUO's research interests include community ecology and biogeography. 